\title{
Biodigestão anaeróbia de dejetos de caprinos e ovinos em reator contínuo de PVC flexível ${ }^{1}$
}

\author{
Danilo G. de Quadros', André de P. M. Oliver ${ }^{3}$, Ueliton Regis4, Renata Valladares ${ }^{5}$, Pedro H. F. de Souza ${ }^{6}$ \& Edivaldo de J. Ferreira ${ }^{3}$
}

\section{RESUMO}

A escassez de fontes energéticas e as altas taxas de mortalidade do rebanho são dois grandes problemas para os agricultores familiares no semiárido brasileiro. De setembro de 2006 a abril de 2007 um reator contínuo com gasômetro em PVC flexível, com $33 \mathrm{~m}^{3}$ de volume, instalado na Estação Experimental da EBDA, Jaguarari, Estado da Bahia, foi monitorado quanto aos parâmetros bioquímicos, microbiológicos e parasitários do afluente e efluente, sendo avaliadas a produção e a composição do biogás, além da utilização do biofertilizante em capim-elefante. Com o manejo adequado, 0 poder poluente dos dejetos foi reduzido significativamente. Microbiologicamente, a eficiência de remoção de coliformes totais e fecais se manteve acima de $98 \%$ enquanto os ovos dos principais endoparasitos foram eliminados com 0 tratamento. A produção de biogás foi de $0,061 \mathrm{~m}^{3} \mathrm{~kg}^{-1}$ de esterco. Basicamente, o biogás apresentou, em sua composição, 58 e 34\% de metano e gás carbônico, respectivamente. 0 biofertilizante $(\mathrm{pH} 7,5)$ foi uma boa fonte de nutrientes, sobretudo de nitrogênio (64 g 100L-1, 80\% na forma amoniacal) e potássio (214 g 100 $\mathrm{L}^{-1}$ ), aumentando a produção de forragem sem alterações significativas na composição bromatológica, digestibilidade "in vitro" da matéria seca e teor de minerais.

Palavraschave: biofertilizante, biogás, energia renovável, esterco

\section{Anaerobic digestion of goat and sheep wastes in a continuous reactor of flexible PVC}

\begin{abstract}
The scarcity of energy resources and the high livestock mortality rates are perpetual problems for small farmers of the Brazilian semi-arid region. From September 2006 to April 2007 a continuous reactor, of $33 \mathrm{~m}^{3}$ with gasometer in PVC flexible film, was installed at the EBDA Experimental Station, Jaguarari, Bahia State and the affluent and effluent biochemical, microbiological, and parasitological characteristics were monitored, the biogas production and composition being evaluated, as well as the use of the biofertilizer in elephant grass. With adequate management, the pollution power of residues reduced significantly. Microbiologically, the efficiency of total and fecal coliforms remotion was above $98 \%$, when the main endoparasite eggs were eliminated after treatment. The biogas production was $0.061 \mathrm{~m}^{3} \mathrm{~kg}^{-1}$ of manure. The biogas showed in its composition basically 58 and $34 \%$ of methane and carbonic dioxide, respectively. The biofertilizer (pH 7.5) was a great source of nutrients, mainly nitrogen (64 g 100 - $-1,80 \%$ ammoniacal form) and potassium (214 g 100 - $\left.{ }^{-1}\right)$, increasing forage production, without significant changes in the chemical composition, "in vitro" dry matter digestibility, and mineral content.
\end{abstract}

Key words biofertilizer, biogas, renewable energy, manure

\footnotetext{
${ }^{1}$ Financiado pelo CNPq e USAID

2 NEPPA/UNEB - Campus IX. CEP 47800-000, Barreira, BA. Fone: (77) 3612-6744. E-mail: uneb neppa@yahoo.com.br

3 WINROCK. CEP 41830-001, Salvador, BA. Fone: (71) 3248-0701. E-mail: andre@oliver.adm.br

4 EBDA. CEP 41635-150, Salvador, BA. Fone: (71) 3116-1800. E-mail: uregis@hotmail.com

${ }^{5}$ Ambiental PV. CEP 40140-380, Salvador, BA. Fone: (71) 3624-3199. E-mail: renata@ambientalpv.com

${ }^{6}$ UNEB - Campus III. CEP 48900-000, Juazeiro, BA. Fone: (74) 3611-0107. E-mail: rbnsouza@bol.com.br
} 


\section{INTRODUÇÃO}

O semiárido brasileiro ocupa área de aproximadamente $900.000 \mathrm{~km}^{2}$, cerca de $10 \%$ do território do País. Neste contexto, a caprino-ovinocultura é uma das alternativas socioeconômicas mais importantes, com destaque para a agricultura familiar.

Um grave problema enfrentado pelos agricultores familiares é a escassez de fontes energéticas para fins produtivos, cocção, resfriamento, aquecimento e iluminação. A lenha é fonte de calor comum para uso na cozinha, porém é um recurso escasso e que deve ser preservado. Em 2004, o setor residencial consumiu cerca de 26 milhões de toneladas de lenha e a demanda tem crescido nos últimos anos pelo aumento dos custos do seu substituto direto, o gás liquefeito de petróleo (GLP), vendido em botijões (Goldemberg \& Lucon, 2007). Na maioria das áreas rurais os combustíveis mais limpos para cocção (querosene, GLP e gás natural) são intermitentes ou inexistem, devido à falta de infraestrutura de distribuição e comercialização, além de serem relativamente mais caros que os tradicionais (lenha e carvão vegetal) disponíveis nessas áreas (Sanga, 2004). Em países que não produzem petróleo ou gás natural, eles são importados e seus preços variam constantemente em consonância com o preço do petróleo no mercado internacional. A situação socioeconômica precária e o baixo poder aquisitivo da população impedem a penetração desses combustíveis nessas áreas, levando a população a continuar utilizando combustíveis tradicionais em fogões ineficientes, que são disponíveis em abundância a custos menores e até nenhum (Sanga, 2004).

O desmatamento, entretanto, agrava a seca, a perda de solo por erosão e coloca em perigo a flora e fauna do ecossistema. Além desses impactos negativos sobre o meio ambiente, a queima de lenha para uso doméstico causa graves problemas de saúde principalmente em mulheres e crianças, que ficam expostas diariamente à fumaça. A concentração dos gases poluentes em ambientes fechados, mesmo com uso de fogões eficientes, é maior que os níveis indicados pela Organização Mundial de Saúde e Agência Ambiental dos Estados Unidos, aumentando o risco das infecções agudas respiratórias e outras doenças, tais como o câncer e a tuberculose, as quais estão entre as quatro maiores causas de doenças e de mortes nos países em desenvolvimento.

O uso de querosene nos candeeiros para iluminação também contribui para a poluição do ar dentro de casa enquanto as pilhas usadas para rádios e outros fins representam custo significativo no orçamento familiar, além de causar poluição do solo e da água, quando são descartadas negligentemente.

As principais fontes de energia para o consumo no segmento agropecuário foram: óleo diesel (58\%), lenha (26\%), energia elétrica (15\%) e outros (1\%), com elevação dos preços pagos pela energia, pois os preços do óleo diesel, da lenha e da energia elétrica, aumentaram 41, 52 e 36\%, respectivamente, no triênio 2002-2004 (Esperancini et al., 2007). Os impactos da elevação do custo de energia se fazem sentir com maior intensidade no setor rural de mais baixa renda, em geral menos capitalizado e com menores condições de arcar com essa elevação de custos, tanto no que diz respeito ao consumo doméstico quanto para as atividades de produção.

O manejo inadequado dos dejetos é outro grave impasse atuando frequentemente como vetor de doenças e contaminando a água e o solo. Os problemas epidemiológicos constatados no meio rural estão relacionados com os agentes causadores de infecções dentro das propriedades; portanto, a prevenção dos fatores que contribuem para sua ocorrência protege os animais contra o risco de infecções e o público, contra zoonoses ou outros riscos sanitários provocados pelo lançamento de resíduos no ambiente (Oliveira, 1997).

A biodigestão anaeróbia consiste na fermentação com ausência de oxigênio de dejetos animais, plantas e lixo (doméstico e urbano) através de bactérias anaeróbias que sintetizam a matéria orgânica transformando-a em metano e dióxido de carbono, principais componentes do biogás (Castro \& Cortez, 1998).

A utilização de biodigestores contribui para integração e sustentabilidade das atividades agropecuárias aproveitando o dejeto ao qual, normalmente, é dado pouco ou mesmo nenhum valor comercial, convertendo-o em duas grandes fontes de desenvolvimento: em energia e adubo. Para cocção, o biogás é o combustível mais limpo de todos, seguido do GLP e querosene em fogão pressurizado, conforme a escada energética (Sanga, 2004). O biogás e o biofertilizante permitem aumento da produção agrícola e a transformação dos produtos tradicionais rurais, agregando valor, organizando a produção, aumentando a conservação dos produtos e melhorando a logística de comercialização para os agricultores familiares.

O objetivo do presente trabalho foi avaliar o aproveitamento de dejetos de caprinos e ovinos em um biodigestor contínuo de PVC flexível, monitorando os aspectos bioquímicos, microbiológicos e parasitários do afluente e efluente, a produção e a composição do biogás, além da massa de forragem, composição bromatológica e mineral do capim-elefante adubado com biofertilizante.

\section{MATERIAL E MÉTODOS}

Um reator contínuo modelo canadense, também conhecido como da marinha, foi utilizado com gasômetro em laminado de PVC flexível, instalado na Estação Experimental de Caraíbas, da EBDA, em Pilar (Jaguarari, Bahia, latitude 9० 51' 43” S, longitude 3953' 50” W). A região apresenta precipitação anual de $400 \mathrm{~mm}$ com chuvas ocorrendo principalmente nos meses de novembro a abril e temperatura média anual de $25^{\circ} \mathrm{C}$.

O reator, de $33 \mathrm{~m}^{3}$, apresentou dimensões de $9 \mathrm{~m}$ de comprimento por 1,5 m de profundidade, base menor e maior de 1,9 e 3,0 m, respectivamente. As caixas de entrada e de saída foram construídas em alvenaria com canos de PVC rígido de $150 \mathrm{~mm}$, medindo 1 x 1 x 0,8 m de largura, comprimento e profundidade, respectivamente. O reator foi dimensionado para tempo de retenção de 45 dias.

Primeiro se retiraram os paus e pedras do aprisco de chão batido no qual os animais passaram as noites; em seguida, 
no manejo diário o esterco foi obtido por varreção, com cuidado para não trazer terra; após colocado na caixa de entrada, foi diluído na proporção 1:4, ou seja, $50 \mathrm{~kg}$ de esterco em 200 L de água, mantendo-o em imersão por 24 h, para amolecimento; no dia seguinte se recolheram as cíbalas sobrenadantes, com o auxílio de uma rede de metal, ou pá, que foram amassadas com ajuda de um pilão adaptado. Este processo foi possível com a divisão da caixa de entrada em dois compartimentos interligados na parte inferior; no segundo compartimento, o afluente tem acesso ao biodigestor; este procedimento de manejo foi fundamental, haja vista que as cíbalas integrais se acumulam na superfície do conteúdo interno do biodigestor formando uma crosta não fermentada impedindo, assim, a produção de biogás.

No dia 29.10.2006, amostragens de 1,3 L do afluente e efluente foram realizadas em triplicata. As amostras foram refrigeradas e transportadas ao Laboratório do SENAI-CETIND, em Lauro de Freitas, Bahia, para análise da demanda bioquímica de oxigênio (DBO), demanda química de oxigênio (DQO), nitrogênio (N), fósforo (P), potássio (K), sólidos totais (ST) e voláteis (SV). Outras amostras, acondicionadas em coletores estéreis de $150 \mathrm{~mL}$, foram refrigeradas e levadas ao Laboratório da UNEB, Campus III, em Juazeiro, Bahia, para mensuração do $\mathrm{pH}$ e da condutividade elétrica (CE) (APHA, 2000).

Na mesma ocasião se colheram amostras de $150 \mathrm{~mL}$ em coletores estéreis do afluente e do efluente, seis repetições por estágio, refrigeradas e levadas para análise coproparasitológica com contagem de ovos de helmintos e oócitos de protozoários, no Laboratório de Parasitologia da Universidade Federal da Bahia, pela técnica adaptada de Gordon \& Whitlock (1939). Os dados da contagem de ovos por grama de fezes (OPG) de Strongyloidea e Trichuris spp., além de oócitos de Eimeria spp., foram transformados em $\log \mathrm{x}+5$, enquanto os dados de Moniezia sp. (positivo ou negativo), pela distribuição binomial, foram transformados em arco seno da raiz quadrada de $\mathrm{x} / 100$.

No dia 30.11.2006, três amostras de aproximadamente $250 \mathrm{~mL}$ foram colhidas em frascos de vidro, conservadas em tiossulfato de sódio, EDTA e refrigeração, transportadas ao Laboratório do SENAI-CETIND para estimativa do número mais provável (NMP) de coliformes totais e fecais (APHA, 2000).

Durante 12 meses uma capineira de capim-elefante (Pennisetum purpureum Schum.), irrigada por sulcos, localizada a cerca de $80 \mathrm{~m}$ do biodigestor recebeu, na metade da área de 0,5 ha, o biofertilizante, via solo na dose de $0,5 \mathrm{~L} \mathrm{~m}^{-2}$. A distribuição na área foi progressiva, $100 \mathrm{~m}^{2} \mathrm{dia}^{-1}$, objetivando-se a produção de forragem para o rebanho da Estação. As amostragens foram realizadas na área que recebeu, ou não, biofertilizante.

Quatro amostras de solo foram retiradas por área, na profundidade de 0-20 cm, compondo uma amostra composta, as quais foram levadas ao Laboratório de Solos da UNEB campus III, Juazeiro, para análises físico-químicas.

As propriedades físicas e químicas do solo da área que recebeu, ou não, o biofertilizante, não variaram, exceto pelo acúmulo de fósforo na gleba adubada, na qual a densidade real foi ligeiramente menor (Tabela 1). A declividade no sentido da área adubada à não-adubada e o sistema de irrigação por sulcos contribuíram, de certa forma, para o transporte de nutrientes solúveis, resultando equilíbrio das condições para o desenvolvimento do capim.

Tabela 1. Propriedades físicas e químicas do solo da capineira de capimelefante irrigada e adubada com biofertilizante

\begin{tabular}{|c|c|c|c|}
\hline Atributos & Unidade & $\begin{array}{c}\text { Sem } \\
\text { biofertilizante }\end{array}$ & $\begin{array}{c}\text { Com } \\
\text { biofertilizante }\end{array}$ \\
\hline \multicolumn{4}{|c|}{ Propriedades fisicas } \\
\hline Areias & $\mathrm{g} \mathrm{kg}^{-1}$ & 634 & 589 \\
\hline Silte & $\mathrm{g} \mathrm{kg}^{-1}$ & 182 & 202 \\
\hline Argila total & $\mathrm{g} \mathrm{kg}^{-1}$ & 184 & 109 \\
\hline Argila natural & $\mathrm{g} \mathrm{kg}^{-1}$ & 42,2 & 50,6 \\
\hline Densidade real & $\mathrm{mg} \mathrm{dm}^{-3}$ & 2,68 & 2,58 \\
\hline \multicolumn{4}{|c|}{ Propriedades químicas ${ }^{1}$} \\
\hline pH & & 6,8 & 6,9 \\
\hline$P$ & $\mathrm{mg} \mathrm{dm}^{-3}$ & 8,31 & 38,0 \\
\hline K & $\mathrm{mmol}_{\mathrm{c}} \mathrm{dm}^{-3}$ & 2,02 & 1,82 \\
\hline $\mathrm{Ca}$ & $\mathrm{mmol}_{\mathrm{c}}^{\mathrm{c}} \mathrm{dm}^{-3}$ & 13,5 & 12,9 \\
\hline $\mathrm{Mg}$ & $\mathrm{mmol}_{\mathrm{c}} \mathrm{dm}^{-3}$ & 5,2 & 6 \\
\hline $\mathrm{Na}$ & $\mathrm{mmol}_{\mathrm{c}} \mathrm{dm}^{-3}$ & 0,16 & 0,18 \\
\hline $\mathrm{Al}$ & $\mathrm{mmol}_{\mathrm{c}} \mathrm{dm}^{-3}$ & 0 & 0 \\
\hline $\mathrm{H}+\mathrm{Al}$ & $\mathrm{mmol}_{\mathrm{c}} \mathrm{dm}^{-3}$ & 2,1 & 1,8 \\
\hline $\mathrm{SB}$ & $\mathrm{mmol}_{\mathrm{c}}^{\mathrm{c}} \mathrm{dm}^{-3}$ & 20,72 & 20,72 \\
\hline СTC & $\mathrm{mmol}_{\mathrm{c}} \mathrm{dm}^{-3}$ & 22,82 & 22,52 \\
\hline V & $\%$ & 90,8 & 92,1 \\
\hline
\end{tabular}

O índice de saturação por bases (V) esteve acima dos 70\% indicado para a formação e 60\%, para manutenção, recomendados por Werner et al. (1996) para capim-elefante; no semiárido é comum a ocorrência de solos com boa fertilidade natural, como os Luvissolos não hidromórficos, horizonte A fraco e B avermelhado eutrófico, argila (Ta), B textural.

No momento do corte o capim-elefante apresentou idade de rebrotação de 40 dias, com altura média de 1,20 m. Para quantificação da massa verde (MV) e seca foram cortadas, rente ao solo, duas amostras em $1 \mathrm{~m}$ linear por área; essas amostras foram pesadas e retiradas subamostras para quantificação do teor de matéria seca (MS). Calculou-se o rendimento de massa verde e seca por hectare considerando-se a massa por metro linear multiplicado pela quantidade de metros lineares por hectare, sendo o espaçamento entre linhas de $0,9 \mathrm{~m}$. As subamostras foram enviadas ao Laboratório de Bromatologia da Empresa Brasileira de Pesquisa Agropecuária - EMBRAPA Semiárido, em Petrolina, Pernambuco, para análise dos teores de MS em estufa com circulação forçada de ar a $60{ }^{\circ} \mathrm{C}$ durante 72 h e após moagem em moinho tipo Willey, em estufa a $105^{\circ} \mathrm{C}$ por $24 \mathrm{~h}$, cinzas, em mulfa a $550{ }^{\circ} \mathrm{C}$, por $6 \mathrm{~h}$; proteína bruta (PB), pelo método semimicro Kjelhahl; fibra em detergente neutro (FDN) e ácido (FDA), pelo método de Van Soest, e digestibilidade in vitro da matéria seca (DIVMS).

Três amostras compostas constituída, cada uma, de 10 lâminas foliares de capim-elefante, as primeiras totalmente 
expandidas por perfilho (estádio observado com a exposição da lígula), foram colhidas em cada área e enviadas ao Laboratório de Análises de Solo e Planta da Valexport, em Petrolina, para análise dos teores dos macronutrientes: nitrogênio $(\mathrm{N})$, fósforo $(\mathrm{P})$, potássio $(\mathrm{K})$, cálcio $(\mathrm{Ca})$, magnésio $(\mathrm{Mg})$ e micronutrientes: boro $(\mathrm{B})$, zinco $(\mathrm{Zn})$, cobre $(\mathrm{Cu})$, ferro $(\mathrm{Fe})$, manganês $(\mathrm{Mn})$ e sódio $(\mathrm{Na})$.

Quantificou-se a produção do biogás utilizando-se gasômetro da marca LAO modelo G1, seguindo-se as recomendações do fabricante. Para a colheita do biogás se utilizaram seringas de polipropileno de $60 \mathrm{~mL}$, com bico tipo slim, acoplada a válvula de três estágios e mangueira de silicone de $1400 \mathrm{~mm}$ conectada à mangueira de acesso do biogás ao fogão por meio de uma seringa de $5 \mathrm{~mL}$; logo após a colheita, em triplicata, as amostras foram acondicionadas em caixa de polietileno (isopor), para evitar alterações na temperatura e luminosidade, e enviadas ao Laboratório do Hidrogênio, na Universidade de Campinas (UNICAMP), para análise dos teores de metano $\left(\mathrm{CH}_{4}\right)$, gás carbônico $\left(\mathrm{CO}_{2}\right)$, nitrogênio $\left(\mathrm{N}_{2}\right)$ e oxigênio $\left(\mathrm{O}_{2}\right)$, por cromatografia gasosa (aparelho marca HP, modelo 5890a, limite de detecção de $0,1 \mathrm{~mol} \mathrm{~mol}^{-1}$ ) e microcromatografia gasosa (aparelho aparelho marca Agilent, limite de detecção de $0,01 \% \mathrm{~mol} \mathrm{~mol}^{-1}$ ).

Os dados foram tabulados no programa Excel, o qual foi utilizado no cálculo das médias, desvios, erro padrão e coeficiente de variação.

\section{RESULTADOS E DISCUSSÃO}

A concentração da DBO apresentou diminuição de 50\%, com a passagem do material pelo biodigestor (Tabela 2), eficiência de redução inferior a 75\% observada por Campos et al. (2005), tratando laboratorialmente dejetos da suinocultura em reator de fluxo ascendente com manta de lodo (UASB); entretanto, quando comparada com a magnitude da remoção da DBO, o valor obtido neste trabalho (915 $\mathrm{mg} \mathrm{L}^{-1}$ ) foi maior em relação ao da encontrada por esses autores (670 $\mathrm{mg} \mathrm{L}^{-1}$ ).

A DBO média do efluente obtida neste trabalho foi menor que a média $1834 \mathrm{mg} \mathrm{L}^{-1}$ encontrada por Fernandes \& Oliveira (2006), tratando dejetos de suínos, originalmente com DBO de 7.557 a $11.640 \mathrm{mg} \mathrm{L}^{-1}$, em reator compartimentado (ABR); contudo, 13\% superior a $799 \mathrm{mg} \mathrm{L}^{-1}$, quando esses autores os processaram em dois estágios, primeiro reator compartimentado seguido de UASB.

Houve redução de $84 \%$ na DQO com o tratamento, valor superior aos $78 \%$ encontrados por Campos et al. (2005) tratando laboratorialmente dejetos suínos em reator UASB. Como na DBO se mede apenas a fração biodegradável, quanto mais este valor se aproximar da DQO significa que mais facilmente biodegradável será o efluente. A relação DQO:DBO do afluente, quanto ao efluente, diminuiu de 9,7 para 3,0, respectivamente.

As amostras colhidas nas caixas de entrada e saída foram bem heterogêneas quanto à concentração de ST e SV, com média de 140 e $111 \mathrm{~g} \mathrm{~L}^{-1}$, respectivamente (Tabela 2); entretanto, Amorim et al. (2004) observaram redução de 36\% de
Tabela 2. Parâmetros bioquímicos e microbiológicos em biodigestor contínuo com gasômetro em PVC flexível, aproveitando-se dejetos da caprino-ovinocultura

\begin{tabular}{|c|c|c|c|c|c|c|}
\hline \multirow{2}{*}{ Parâmetro ${ }^{1}$} & \multicolumn{3}{|c|}{ Afluente } & \multicolumn{3}{|c|}{ Efluente } \\
\hline & Média & $\mathrm{EP}^{3}$ & $\mathrm{CV}^{4}(\%)$ & Média & EP & CV (\%) \\
\hline \multicolumn{7}{|c|}{ Parâmetros bioquímicos } \\
\hline $\mathrm{DBO}\left(\mathrm{mg} \mathrm{L}^{-1}\right)$ & 1831 & 56,5 & 5,34 & 916 & 62,5 & 11,8 \\
\hline $\mathrm{DQO}\left(\mathrm{mg} \mathrm{L}^{-1}\right)$ & 17808 & 719 & 6,99 & 2833 & 784 & 47,9 \\
\hline $\mathrm{ST}\left(\mathrm{g} \mathrm{L}^{-1}\right)$ & 143,7 & 17,4 & 20,9 & 202,7 & 64,7 & 55,3 \\
\hline$S V\left(g L^{-1}\right)$ & 82,5 & 41,5 & 87,2 & 171,0 & 63,1 & 63,9 \\
\hline$N\left(m g L^{-1}\right)$ & 721 & 93,3 & 22,4 & 557 & 74,2 & 23,1 \\
\hline$P\left(m g L^{-1}\right)$ & 33,4 & 5,34 & 27,7 & 28 & 1,03 & 6,49 \\
\hline $\mathrm{K}\left(\mathrm{mg} \mathrm{L}^{-1}\right)$ & 2178 & 54,3 & 4,0 & 2103 & 46,7 & 3,84 \\
\hline $\mathrm{N}-\mathrm{NH}_{3}\left(\mathrm{mg} \mathrm{L}^{-1}\right)$ & 576 & 194 & 58,4 & 526 & 106 & 35,0 \\
\hline pH & 6,13 & 0,00 & 0,00 & 7,50 & 0,06 & 1,33 \\
\hline CE & 5,33 & 0,26 & 8,33 & 5,43 & 0,07 & 2,13 \\
\hline \multicolumn{7}{|c|}{ Parâmetros microbiológicos } \\
\hline $\begin{array}{l}\text { Coliformes totais } \\
\left(\text { NMP }^{2} \times 10^{5}\right)\end{array}$ & 500 & 115 & 40,00 & 6,33 & 1,67 & 45,6 \\
\hline $\begin{array}{l}\text { Coliformes fecais } \\
\left(\text { NMP }^{2} \times 10^{5}\right)\end{array}$ & 433 & 66,7 & 26,6 & 5,33 & 1,45 & 47,2 \\
\hline
\end{tabular}

${ }^{1}$ DBO - demanda bioquímica de oxigênio, DQO - demanda química de oxigênio, ST - sólidos totais, $\mathrm{SV}$ - sólidos voláteis, $\mathrm{N}$ - nitrogênio, $\mathrm{N}-\mathrm{NH}_{3}-\mathrm{N}$ amoniacal, $\mathrm{P}$ - fósforo, $\mathrm{K}$ - potássio, $\mathrm{pH}$ - potencial hidrogeniônico, $\mathrm{CE}$ - condutividade elétrica; ${ }^{2} \mathrm{NMP}$ - número mais provável; ${ }^{3} \mathrm{EP}$ - erro padrão da média; ${ }^{4} \mathrm{CV}$ - coeficiente de variação

SV no efluente em comparação com o afluente quando avaliaram a digestão anaeróbia de dejetos de caprinos em biodigestores modelo batelada, adotando tempo de permanência entre 12 e 20 semanas, conforme as estações do ano.

Considerando os teores de ST obtidos neste trabalho, a taxa de diluição adotada na rotina de manejo do biodigestor mostrou-se adequada pois, segundo Breton et al. (2004), antes da colocação do esterco no biodigestor é importante a mistura com água suficiente para atingir conteúdos de 80 a $160 \mathrm{~g} \mathrm{~L}^{-1}$, mantendo a produção de gás. Orrico et al. (2007) observaram aumento dos percentuais de ST nas fezes de caprinos, com o avançar da idade, sendo de 29,1 e 43,1\% em animais abaixo e acima de oito meses, respectivamente, alimentados com diferentes relações volumoso:concentrado.

A condutividade elétrica não variou expressivamente com o estágio, antes ou depois do tratamento, com média geral de 5,38 (Tabela 2), destoando das observações de Fregoso et al. (2001). Por outro lado, o pH aumentou cerca de $20 \%$ com a passagem dos dejetos pelo reator, atingindo $\mathrm{pH}$ 7,5 (Tabela 2). Mudanças no $\mathrm{pH}$ do meio afetam sensivelmente as bactérias envolvidas no processo de digestão. A faixa de $\mathrm{pH}$ na operação dos biodigestores é de 6,0 a 8,0, tendo como ponto ideal $\mathrm{pH} 7,0$, que ocorre normalmente quando o reator está funcionando bem.

Não houve diferenças marcantes na concentração de N, $\mathrm{P}$ e $\mathrm{K}$ nas amostras do afluente e do efluente considerando-se, portanto, os dados médios, o biofertilizante apresentou conteúdos de N, P e K, de 639; 30,5 e $2141 \mathrm{mg} \mathrm{L}^{-1}$, respectivamente; considerando-se a produção de $250 \mathrm{~L} \mathrm{~d}^{-1}$, resultaria em: 58,3 $\mathrm{kg} \mathrm{N}$ ano-1 $^{-1}$ que equivaleria a $291 \mathrm{~kg}$ de sulfato de amônio ( $20 \%$ de N); $2,8 \mathrm{~kg}^{2} \mathrm{ano}^{-1}$ de P, correspondente a $35 \mathrm{~kg}$ de superfosfato simples (18\% de $\left.\mathrm{P}_{2} \mathrm{O}_{5}\right)$, e $195 \mathrm{~kg}$ de $\mathrm{K} \mathrm{ano}^{-1}$, $404 \mathrm{~kg}$ de cloreto de potássio (58\% de $\mathrm{K}_{2} \mathrm{O}$ ). Os teores de $\mathrm{N}$, P e $\mathrm{K}$ no biofertilizante encontrados 
neste trabalho foram considerados satisfatórios (Tabela 2) e superiores aos observados por Fregoso et al. (2001), que trataram dejetos da suinocultura em biodigestor de polietileno tubular, com caixa de entrada e saída (tipo FAO), em 10, 77 e 488\%, respectivamente para N, P e K. Os efeitos da utilização de biofertilizantes provenientes de biodigestores são benéficos na produção de culturas agrícolas, como ficou demonstrado por Villela Júnior et al. (2003).

Do total do $\mathrm{N}$, cerca de $80 \%$ foram na forma amoniacal $\left(\mathrm{N}-\mathrm{NH}_{3}\right)$ (Tabela 2$)$, que oferece vantagens para absorção pela planta já que ela é capaz, sobremaneira, de utilizar o $\mathrm{N}$ na forma de amônio (Breton et al., 2004). A proporção de N$\mathrm{NH}_{3}$ obtida no presente trabalho, foi de $80 \%$. Fries \& Aita (1990), testando a aplicação de esterco e biofertilizante em sorgo observaram aumento nos teores de N prontamente disponível, refletindo em maior absorção pelas plantas, quando aplicaram o biofertilizante.

Foi significativa a diminuição no NMP de coliformes totais $(98,7 \%)$ e fecais $(98,8 \%)$ no efluente, em relação ao afluente (Tabela 2). Os valores de NMP de coliformes fecais e totais no efluente observados neste trabalho, foram considerados dentro da normalidade observando-se os resultados de Amaral et al. (2004) e tratando dejetos de bovinos leiteiros em biodigestores modelos Indiano e Chinês; contudo, a eficiência de redução foi menor que os 99,99\% encontrados por Amorim et al. (2004) e de 99,8 a 100\%, por Amorim (2005), tratando dejetos de caprinos em biodigestores modelo batelada por 24 a 29 semanas.

A contagem de OPG dos nematódeos da superfamília Strongyloidea que mais acometem o rebanho, reduziu significativamente com o tratamento dos dejetos no biodigestor, ou seja, cerca de 96\% de eficiência (Tabela 3).

Tabela 3. Contagem de ovos por grama de fezes (OPG) de Strongyloidea e Trichuris spp., de oócitos por grama de fezes (OOPG) de Eimeria spp. e prevalência de Monizezia sp. em biodigestor contínuo em PVC flexível, tratando dejetos da caprino-ovinocultura

\begin{tabular}{lcccccccc}
\hline \multirow{2}{*}{ Parasito } & \multicolumn{3}{c}{ Afluente } & & \multicolumn{3}{c}{ Efluente } \\
\cline { 2 - 3 } \cline { 6 - 8 } & Média & EP & CV $^{2}$ (\%) & & Média & EP & CV (\%) \\
Strongyloidea & 383 & 0,04 & 3,66 & & 16,7 & 0,22 & 51,4 \\
Eimeria spp. & 1417 & 0,08 & 6,26 & & 592 & 0,12 & 10,5 \\
Trichuris spp. & 66,7 & 0,28 & 43,2 & & 16,7 & 0,22 & 58,7 \\
Moniezia sp. ${ }^{1}$ & $66,7 \%$ & & & & $50,0 \%$ & & \\
\hline
\end{tabular}

${ }_{1}^{1}$ Percentual de amostras positivas (+) ; ${ }^{2}$ EP-erro padrão da média; ${ }^{3} \mathrm{CV}$-coeficiente de variação

Os poucos ovos encontrados no biofertilizante se apresentaram com as larvas mortas. A viabilidade de ovos de nematódeos Strongyloidea foi de 35 dias, em experimento com tanques cilíndricos de $200 \mathrm{~L}$, atuando como biodigestores, tratando $83 \mathrm{~kg}$ de dejetos de bovinos leiteiros, no qual a infectividade das larvas dos gêneros Haemonchus, Cooperia e Oesophagostomum, foi controlada após 14 dias de retenção enquanto os gêneros Trichostrongylus e Ostertagia, após 35 dias (Mentz et al., 2004a).

Para Amaral et al. (2004), o processo de biodigestão promoveu a redução da contagem de ovos de helmintos em dejetos bovinos; entretanto, 40 dias de retenção foram insufi- cientes para impedir a sobrevivência das larvas, após a coprocultura do efluente; para o trematódeo Fasciola hepatica dos bovinos, o período de retenção do material em biodigestão anaeróbia não deve ser inferior a 42 dias, antes do seu retorno ao ambiente (Mentz et al., 2004b).

A biodigestão de dejetos reduziu significativamente a contagem de oócitos no efluente, com valores médios 58\% menores (Tabela 3), em comparação com o afluente. A Eimeria spp. são protozoários coccídicos que afetam diferentes sistemas de produção, sendo mais frequente em animais confinados.

Encontraram-se poucos ovos do nematódeo Trichuris spp., que vive na mucosa do cólon (intestino grosso), tanto no afluente quanto no efluente (Tabela 3), porém ovos do cestódeo Moniezia sp., parasito do intestino delgado que geralmente ocorre em animais jovens, foram identificados em $58,3 \%$ das amostras, independente do local da amostragem, caixa de entrada ou saída (Tabela 3).

A produção média de biogás foi de $0,061 \mathrm{~m}^{3} \mathrm{~kg}^{-1}$ de esterco, ou $0,003 \mathrm{~m}^{3} \mathrm{~kg}^{-1}$ de substrato (Tabela 4). Considerando-se a produção diária de esterco de 50 kg (100 animais presos à noite), resultaria em $3,0 \mathrm{~m}^{3} \mathrm{~d}^{-1}$ de biogás, ou 91,9 $\mathrm{m}^{3}$ mês $^{-1}$, equivalente a 2,8 botijões de $13 \mathrm{~kg}$ de GLP (33 $\mathrm{m}^{3}$ de biogás $=1$ botijão). No ano, a produção foi estimada em $1.118 \mathrm{~m}^{3}$ de biogás, que correspondem a 33,9 botijões de GLP. Se o valor de cada botijão é R \$ 33,00, a produção anual de biogás corresponderia a 1.118 reais. A produção de biogás convertida em eletricidade $\left(5,5 \mathrm{kWh} \mathrm{m}^{-3}\right)$ de biogás, segundo Magalhães et al. (2004), resultaria em $505 \mathrm{kWh}$ mês $^{-1}$, ou $6.151 \mathrm{kWh}$ ano $^{-1}$ e, se o consumo médio mensal de uma residência é de 200 kWh, o biogás produzido manteria, durante um ano, 2,6 lares.

Os resultados obtidos no presente trabalho estiveram dentro da faixa de 0,043 a $0,103 \mathrm{~m}^{3} \mathrm{~kg}^{-1}$ de esterco (corrigidos para $20^{\circ} \mathrm{C}$ e $1 \mathrm{~atm}$ ), relatada por Amorim (2005), considerando caprinos da raça Saanen com 90 a 150 dias de idade recebendo dietas com proporção volumoso:concentrado variando de 80:20 a 40:60.

Tabela 4. Produção de biogás em relação ao esterco e substrato, em biodigestor contínuo com gasômetro de manta impermeável, tratando dejetos da caprino-ovinocultura no semiárido

\begin{tabular}{ccc}
\hline \multirow{2}{*}{ Parâmetro } & \multicolumn{2}{c}{ Produção de biogás $\left(\mathbf{m}^{3}\right)$} \\
\cline { 2 - 3 } Média & Por kg esterco & Por L substrato \\
EP' & 0,061 & 0,003 \\
$\mathrm{CV}^{2}(\%)$ & 0,011 & 0,002 \\
\hline
\end{tabular}

${ }^{1}$ EP - erro padrão da média; ${ }^{2} \mathrm{CV}$ - coeficiente de variação

O biogás apresentou, na sua composição, 57,8; 34,4; 5,0, e 2,8\% de $\mathrm{CH}_{4}, \mathrm{CO}_{2}, \mathrm{~N}_{2}$ e $\mathrm{O}_{2}$, respectivamente (Tabela 5). Em biodigestores batelada tratando dejetos de caprinos, o percentual de metano no biogás foi maior nas primeiras duas semanas após o abastecimento atingindo 73,0 e 56,3\%, para verão e outono, com queima após os $4^{\circ}$ e o $12^{\circ}$ dia, respectivamente, o que só ocorreu na $6^{\text {a }}$ semana para os abastecimentos realizados nas estações de inverno e primavera, cujos valores 
Tabela 5. Composição do biogás produzido da biodigestão anaeróbia de dejetos de ovinos e caprinos em biodigestor contínuo de manta de PVC

\begin{tabular}{ccccc}
\hline Gases & Unidade & Média & $\mathrm{EP}^{1}$ & $\mathrm{CV}^{2}$ (\%) \\
$\mathrm{CH}_{4}$ & $\% \mathrm{~mol} \mathrm{~mol}^{-1}$ & 57,8 & 0,26 & 0,8 \\
$\mathrm{CO}_{2}$ & $\% \mathrm{~mol} \mathrm{~mol}^{-1}$ & 34,4 & 0,93 & 4,7 \\
$\mathrm{~N}_{2}$ & $\% \mathrm{~mol} \mathrm{~mol}^{-1}$ & 5,0 & 0,82 & 28,4 \\
$\mathrm{O}_{2}$ & $\% \mathrm{~mol} \mathrm{~mol}^{-1}$ & 2,8 & 0,27 & 16,7 \\
\hline
\end{tabular}

${ }^{1} \mathrm{EP}$ - erro padrão da média; ${ }^{2} \mathrm{CV}$ - coeficiente de variação

foram de 43,2 e 56,1\% de $\mathrm{CH}_{4}$, com queima após 42 e 31 d, respectivamente (Amorim et al., 2004).

As proporções de $\mathrm{CH}_{4}$ e $\mathrm{CO}_{2}$ mensuradas neste trabalho estiveram na faixa de $50-70 \%$ e $30-40 \%$, respectivamente, relatadas por Breton et al. (2004) para composição do biogás, que contém pequenas quantidades de outros gases, como $5-10 \%$ de hidrogênio $\left(\mathrm{H}_{2}\right), 1-2 \%$ de nitrogênio $\left(\mathrm{N}_{2}\right)$ e $0,3 \%$ de vapor d’água.

O capim-elefante colhido na área que recebeu o biofertilizante apresentou MV e MS, 24 e 15\% maiores em relação ao sem adubo, diferenças essas correspondentes a 6,6 e 0,6 t ha $^{-1}$, respectivamente (Tabela 6).

Tabela 6. Massa verde (MV) e seca (MS), em tha-1, de capim-elefante adubado com biofertilizante em biodigestor contínuo aproveitando dejetos da caprino-ovinocultura

\begin{tabular}{|c|c|c|c|c|c|c|}
\hline \multirow{2}{*}{ Parâmetro } & \multicolumn{3}{|c|}{ Sem biofertilizante } & \multicolumn{3}{|c|}{ Com biofertilizante } \\
\hline & Média & $E P^{1}$ & CV $^{2}(\%)$ & Média & EP & CV (\%) \\
\hline MV & 19,6 & 1,6 & 11,2 & 26,2 & 0,88 & 4,80 \\
\hline MS & 3,4 & 24,2 & 1,00 & 4,0 & 0,34 & 12,0 \\
\hline
\end{tabular}

Pereira (2006) testando a aplicação de dejeto líquido de suínos na adubação de capim-braquiária (Brachiaria decumbens), obteve aumentos da MV e MS, na ordem de 200 e $300 \%$, respectivamente. O aumento da produção de forragem é um dos principais motivos para o convencimento dos produtores rurais em utilizarem fertilizantes orgânicos líquidos, em virtude do vigor aparente e da coloração verde-escuro que aparece nas plantas nas parcelas adubadas. O biofertilizante apresenta consistência líquida que facilita a sua aplicação, promovendo em gramíneas forrageiras a aparência tenra e coloração verde escuro. Em razão da maior disponibilidade de nutrientes, o biofertilizante aumentou o rendimento de MS em relação à aplicação do esterco (Fries \& Aita, 1990).

A diferença na magnitude dos valores percentuais de aumento da MV e MS com a adubação se relacionou, sem dúvida, com o menor teor de MS do capim-elefante adubado (15,5\%), em relação ao que não recebeu o biofertilizante (17,7\%) (Tabela 7).

Os teores de PB e FDA observados neste trabalho (Tabela 7) foram maiores que os 7,2-7,4 e 30,4-31,4\%, respectivamente, observados por Santos et al. (2001) em capim-elefante cv. Roxo, cortado a diferentes alturas na frequência de 60 dias nas águas e 90 dias na seca, enquanto os de FDN foram semelhantes.

Na dose testada os teores de macro e microminerais do capim-elefante irrigado não foram afetados expressivamente pela aplicação no biofertilizante via solo (Tabela 8). A relação N-P-K no biofertilizante encontrada neste trabalho, foi de 1,0-0,05-3,0 (Tabela 2), considerada adequada quando comparada com 1,0-0,15-1,6 obtidos na análise foliar (Tabela 8).

Tabela 7. Composição bromatológica e digestibilidade in vitro da matéria seca (DIVMS) do capim-elefante irrigado e adubado com biofertilizante, no semiárido

\begin{tabular}{lrrrrrrrr}
\hline \multirow{2}{*}{ Parâmetro $^{1}$} & \multicolumn{3}{c}{ Sem biofertilizante } & & \multicolumn{3}{c}{ Com biofertilizante } \\
\cline { 2 - 3 } \cline { 7 - 8 } & Média $^{2}$ & EP $^{3}$ & CV $^{4}$ (\%) & & Média & EP & CV (\%) \\
MS & 17,7 & 1,3 & 10,3 & & 15,5 & 1,8 & 16,8 \\
M0 & 87,1 & 0,6 & 1,0 & & 86,7 & 1,4 & 2,4 \\
MM & 12,9 & 0,6 & 6,9 & & 13,3 & 1,4 & 15,4 \\
PB & 8,3 & 0,6 & 10,1 & & 9,7 & 1,1 & 15,5 \\
FDN & 79,0 & 1,4 & 2,5 & & 72,8 & 1,5 & 2,9 \\
FDA & 39,4 & 1,4 & 5,0 & & 40,0 & 1,2 & 4,4 \\
DIVMS & 51,0 & 1,4 & 3,9 & & 56,7 & 3,4 & 8,5 \\
\hline
\end{tabular}

${ }^{1}$ MS - matéria seca, MO - matéria orgânica, MM - matéria mineral, PB - proteína bruta, FDN fibra em detergente neutro, FDA - fibra em detergente ácido; ${ }^{2}$ expressos em \% da MS, exceto MS que está expresso em \% da matéria natural; ${ }^{3} \mathrm{EP}$ - erro padrão da média; ${ }^{4} \mathrm{CV}$ - coeficiente de variação

Tabela 8. Teores de macro e micronutrientes na análise foliar do capimelefante irrigado e adubado com biofertilizante, no semiárido

\begin{tabular}{|c|c|c|c|c|c|c|}
\hline \multirow{2}{*}{ Parâmetro } & \multicolumn{3}{|c|}{ Sem biofertilizante } & \multicolumn{3}{|c|}{ Com biofertilizante } \\
\hline & Média & EP1 & CV $^{2}(\%)$ & Média & EP & CV (\%) \\
\hline$N\left(\mathrm{~g} \mathrm{~kg}^{-1}\right)$ & 15,4 & 1,0 & 11,8 & 19,0 & 1,4 & 12,5 \\
\hline$P\left(g_{k g}^{-1}\right)$ & 2,2 & 6,0 & 124,2 & 2,8 & 0,2 & 11,2 \\
\hline$K\left(\mathrm{~g} \mathrm{~kg}^{-1}\right)$ & 26,5 & 3,3 & 21,6 & 27,4 & 1,7 & 10,6 \\
\hline $\mathrm{Ca}\left(\mathrm{g} \mathrm{kg}^{-1}\right)$ & 8,3 & 1,2 & 25,5 & 6,0 & 1,4 & 40,2 \\
\hline $\operatorname{Mg}\left(\mathrm{g} \mathrm{kg}^{-1}\right)$ & 2,6 & 0,6 & 41,8 & 3,3 & 0,4 & 19,9 \\
\hline$B\left(\mathrm{mg} \mathrm{kg}^{-1}\right)$ & 2,5 & 0,5 & 28,3 & 1,7 & 0,3 & 34,6 \\
\hline $\mathrm{Cu}\left(\mathrm{mg} \mathrm{kg}^{-1}\right)$ & 6,0 & 1,0 & 23,6 & 5,0 & 0,0 & 0,0 \\
\hline $\mathrm{Fe}\left(\mathrm{mg} \mathrm{kg}^{-1}\right)$ & 171,0 & 28,0 & 23,2 & 123,3 & 1,2 & 1,7 \\
\hline $\operatorname{Mn}\left(\mathrm{mg} \mathrm{kg}^{-1}\right)$ & 85,7 & 13,2 & 26,6 & 90,0 & 13,3 & 25,6 \\
\hline $\mathrm{Zn}\left(\mathrm{mg} \mathrm{kg}^{-1}\right)$ & 31,0 & 1,0 & 5,6 & 29,7 & 0,9 & 5,1 \\
\hline $\mathrm{Na}\left(\mathrm{mg} \mathrm{kg}^{-1}\right)$ & 195,3 & 20,6 & 18,2 & 220,7 & 11,9 & 9,3 \\
\hline
\end{tabular}

O capim-elefante exige, para a produção de forragem satisfatória, solos de alta fertilidade. Desde que outros fatores (edáficos, climáticos, vegetativos etc.) não sejam limitantes, a produtividade do capim-elefante é controlada pelo fornecimento de N. Em capineiras, nas quais o capim é cortado e fornecido aos animais fora da área, há pouca reciclagem de nutrientes aumentando a importância da reposição nutritiva.

Os conteúdos de N, P, K, Ca e Mg obtidos no presente trabalho (Tabela 8) estiveram adequados, conforme as recomendações de Werner et al. (1996).

Em relação aos micronutrientes, os conteúdos de $\mathrm{B}, \mathrm{Cu}$, $\mathrm{Fe}, \mathrm{Mn}, \mathrm{Zn}$ e Na encontrados no presente trabalho (Tabela 8), estiveram na faixa adequada, segundo as recomendações de Werner et al. (1996), exceto pelo B, que foi abaixo dos $10-25 \mathrm{mg} \mathrm{kg}^{-1}$.

A estimativa do benefício que o aproveitamento dos dejetos poderia promover considerando-se o efetivo de 17.139.734 
de caprinos e ovinos do nordeste brasileiro, produzindo individualmente $0,5 \mathrm{~kg}$ esterco, somente preso à noite, geraria $3.128 .002 \mathrm{t} \mathrm{ano}^{-1} \mathrm{e}$, se adequadamente manejado, produziria enorme quantidade de biogás, equivalente a 1032 GWh suficientes para abastecer 430.100 residências anualmente consumindo, em média, 200 kWh mês ${ }^{-1}$. No mesmo sentido, a produção de biofertilizante seria equivalente a 18, 2,0 e 25 mil t ano ${ }^{-1}$ de sulfato de amônio, superfosfato simples e cloreto de potássio, respectivamente.

\section{CONCLUSÕES}

1. A eficácia da biodigestão dos dejetos de caprinos e ovinos no saneamento ambiental e na produção de biogás foi satisfatória, considerando-se os parâmetros bioquímicos, microbiológicos e parasitológicos do afluente e do efluente.

2. O NNP de coliformes fecais ainda foi alto, carecendo de maiores estudos quanto ao tempo de retenção.

3. O biofertilizante foi equilibrado para aplicação em pastagens estabelecidas de capim-elefante, com considerável concentração de nutrientes.

\section{LITERATURA CITADA}

Amaral, C. M. C.; Amaral, L. A.; Lucas Júnior, J.; Nascimento, A. A.; Ferreira, D. S.; Machado, M. R. F. Biodigestão anaeróbia de dejetos de bovinos leiteiros submetidos a diferentes tempos de retenção hidráulica. Ciência Rural, v.34, n.6, p.1897-1902, 2004.

Amorim, A. C. Avaliação do potencial de impacto ambiental e do uso da compostagem e biodigestão anaeróbia na produção de caprinos. Jaboticabal: UNESP, 2005. 107p. Tese Doutorado

Amorim, A. C.; Lucas Júnior, J.; Resende, K. T. Biodigestão de dejetos de caprinos obtidos nas diferentes estações do ano. Engenharia Agrícola, v.24, n.1, p.16-24, 2004.

APHA - Standard methods for the examination of water and wastewater. American Public Health Association (APHA)/American Water Works Association (AWWA)/Water Environment Federation (WEF). 20.ed. Washington: American Public Health Association. 2000. 1368p.

Breton, J.; Karlsson, M. F.; La Rocca, F.; Miranda, P. M. S.; Pouliot, M. Renewable energy sources and technologies on farm systems: focusing on Danish scenario. Copenhagen: The Royal Veterinary and Agricultural University, 2004. 126p.

Campos, C. M. M.; Mochizuki, E. T.; Damasceno, L. H. S.; Botelho, C. G. Avaliação do potencial de produção de biogás e da eficiência de tratamento do reator anaeróbio de manta de lodo (UASB) alimentado com dejetos de suínos. Ciência Agrotécnica, v.29, n.4, p.848-856, 2005.

Castro, L. R.; Cortez, L. A. B. Influência da temperatura no desempenho de biodigestores com esterco bovino. Revista Brasileira de Engenharia Agrícola e Ambiental, v.2, n.1, p.97-102, 1998.

Esperancini, M. S. T.; Colen, F.; Bueno, O. C.; Pimentel, A. E. B.; Simon, E. J. Viabilidade técnica e econômica da substituição de fontes convencionais de energia por biogás em assentamento rural do estado de São Paulo. Engenharia Agrícola, v.27, n.1, p.110-118, 2007.
Fernandes, G. F. R.; Oliveira, R. A. Desempenho de processo anaeróbio em dois estágios (reator compartimentado seguido de reator UASB) para tratamento de águas residuárias de suinocultura. Engenharia Agrícola, v.26, n.1, p.243-256, 2006.

Fregoso, M. J. S.; Ferrera-Cerrato, R.; Barra, J. E.; González, G. A.; Santos, J. T.; Gómez, L. B.; Pérez, G. P. Producción de biofertilizantes mediante biodigestion de excreta liquida de cerdo. Terra, v.19, n.4, p.253-362, 2001.

Fries, M. R.; Aita, C. Aplicação de esterco bovino e efluente de biodigestor em um solo Podzólico Vermelho-A marelo: Efeito sobre a produção de matéria seca e absorção de nitrogênio pela cultura do sorgo. Revista do Centro de Ciências Rurais, v.20, n.1-2, p.137-145, 1990.

Goldemberg, J.; Lucon, O. Energia e meio ambiente no Brasil. Estudos Avançados, v.21, n.59, p.7-20, 2007.

Gordon, H. M.; Whitlock, H. V. A new technique for counting nematode eggs in sheep faeces. Journal of the Council of Scientific and Industrial Research, v.12, n.1, p.50-52, 1939.

Magalhães, E. A.; Souza, S. N. M.; Afonso, A. D. L.; Ricieri, R. P. Confecção e avaliação de um sistema de remoção do $\mathrm{CO}_{2}$ contido no biogás. Acta Scientiarum, v.26, n.1, p.11-19, 2004.

Mentz, M. B.; Wiest, J. M.; Gonçalves, P. D. Viability of bovine’s Strongyloidea eggs in a system of anaerobic biodigestion. Parasitologia Latinoamericana, v.59, n.3, p.148-152, 2004a.

Mentz, M. B.; Wiest, J. M.; Gonçalves, P. D. Viabilidade de ovos de Fasciola hepatica de bovinos em sistema de biodigestão anaeróbia. Arquivos Brasileiros de Medicina Veterinária e Zootecnia, v.56, n.4, p.550-553, 2004b.

Oliveira, R. A. Efeito da concentração de sólidos suspensos do afluente no desempenho e características do lodo de reatores anaeróbios de fluxo ascendente com manta de lodo tratando águas residuárias de suinocultura. São Carlos: USP. 1997. 359p. Tese Doutorado

Orrico, A. C. A.; Lucas Júnior, J.; Orrico Júnior, M. A. P. Caracterização e biodigestão anaeróbia dos dejetos de caprinos. Engenharia Agrícola, v.27, n.3, p.639-647, 2007.

Pereira, E. R. Qualidade da água residuária em sistemas de produção e de tratamento de efluentes de suínos e seu reuso no ambiente agrícola. Piracicaba: USP. 2006. 129p. Tese Doutorado

Sanga, G. A. Avaliação de impactos de tecnologias limpas e substituição de combustíveis para cocção em residências urbanas na Tanzânia. Campinas: UNICAMP. 2004. 125p. Dissertação Mestrado

Santos, E. A.; Silva, D. S.; Queiroz Filho, J. L. Composição química do capim-elefante cv. Roxo cortado em diferentes alturas. Revista Brasileira de Zootecnia, v.30, n.1, p.18-23, 2001.

Villela Júnior, L. V. E.; Araújo, J. A. C.; Factor, T. L. Estudo da utilização do efluente de biodigestor no cultivo hidropônico do meloeiro. Revista Brasileira de Engenharia Agrícola e Ambiental, v.7, n.1, p.72-79, 2003.

Werner, J. C.; Paulino, V. T.; Cantarella, H.; Andrade, N. O.; Quaggio, J. A. Forrageiras. In: Van Raij, B.; Cantarela, H.; Quaggio, J. A.; Furlani, A. M. C. (ed.). Recomendações de adubação e calagem para o Estado de São Paulo. Campinas: IAC. 1996. cap.24, p.263-273. Boletim 100. 